\title{
Can Restrictive Approach in Neonatal Transfusion Justify the Clinical Outcome?
}

\author{
Rashmi Parashar $^{1} \cdot$ Neeraj Gupta $^{2} \cdot$ Archana Bajpayee $^{1} \cdot$ Arun Manoj $^{1} \cdot$ Anubhav Gupta $^{1} \mathbb{C}$
}

Received: 24 June 2021 / Accepted: 27 October 2021 / Published online: 18 November 2021

(c) Dr. K C Chaudhuri Foundation 2021

To the Editor: In India majority of the neonatal transfusions are often prescribed on clinician's opinion rather than evidence-based guidelines. Paucity of National Clinical Transfusion guidelines put neonatal transfusion practices in controversy. Sick neonates are heavily transfused groups of patients in critical care. Because of the length of their stay in the neonatal intensive care unit (NICU) and the frequent monitoring of parameters through blood sampling, neonates experience iatrogenic blood loss and may require multiple transfusions. We advocate that neonate transfusions should be critically analyzed in terms of maturity, gestational age, disease effect, and blood volume appropriateness. After evaluating, retrospectively, the transfusion practices in critically ill neonates over $19 \mathrm{mo}$, the incidence of transfusion was $58.4 \%$, PRBC being the most frequently transfused blood component. Several studies have found that the incidence of neonatal transfusion ranges from 20 to $90 \%[1,2]$.

The majority of preterm and extremely low-birth-weight (ELBW) neonates in the NICU are transfused based on laboratory criteria. While transfusion offers an instant benefit in tissue oxygenation, it also inhibits the neonate's immature bone marrow, delays newborn neurodevelopment outcomes, and lengthens hospital stays [3, 4]. We observed that ELBW neonates are an extensively transfused patient population. We found that the mortality was more in extremely preterm newborns than the term neonates. Frequent transfusion to maintain a higher hemoglobin level in ELBW infants gives no further benefit $[3,4]$. So, restricted transfusion approach may be adopted. The association is significant when frequency of transfusion is more than 2 and mortality was higher in late-preterm neonates. Thus, RBC transfusions may have a negative impact on neonatal survival.

Multicentric studies and RCTs are needed to generate evidence for restrictive transfusion and alternatives towards reducing the neonatal transfusion needs. Standard auditing and identifying gray areas should be given importance along with corrective actions.

\section{Declarations}

Conflict of Interest None.

\section{References}

1. Dogra K, Kaur G, Basu S, Chawla D. Red cell transfusion practices in neonatal intensive care unit: an exerience from tertiary care centre. Indian J Hematol Blood Transfus. 2018;34:671-6.

2. dos Santos AM, Guinsburg R, de Almeida MF, et al. Factors associated with red blood cell transfusions in very-low-birthweight preterm infants in Brazilian neonatal units. BMC Pediatr. 2015;15:113.

3. Whyte RK, Kirpalani H, Asztalos EV, et al. Neurodevelopmental outcome of extremely low birth weight infants randomly assigned to restrictive or liberal hemoglobin thresholds for blood transfusion. Pediatrics. 2009;123:207-13.

4. Wang YC, Chan OW, Chiang MC, et al. Red blood cell transfusion and clinical outcomes in extremely low birth weight preterm infants. Pediatr Neonatol. 2017;58:216-22.

Publisher's Note Springer Nature remains neutral with regard to jurisdictional claims in published maps and institutional affiliations.

Anubhav Gupta

dr.anubhavgupta@yahoo.com

1 Department of Transfusion Medicine \& Blood Bank, All India Institute of Medical Sciences, Jodhpur, Rajasthan 342005, India

2 Department of Neonatology, All India Institute of Medical Sciences, Jodhpur, Rajasthan, India 